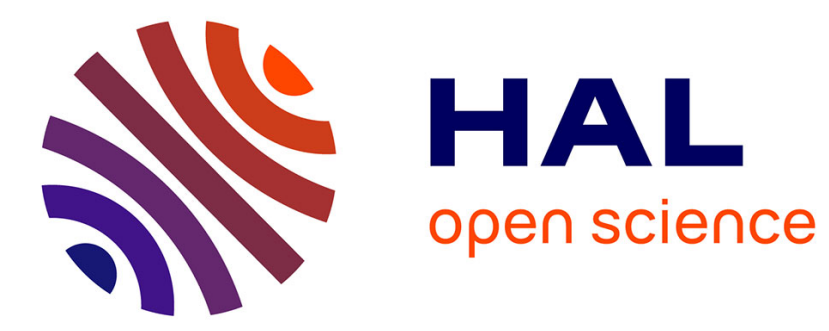

\title{
On the spectra of nozzle-exit velocity disturbances in initially nominally turbulent, transitional jets
}

Christophe Bogey, Olivier Marsden, Christophe Bailly

\section{To cite this version:}

Christophe Bogey, Olivier Marsden, Christophe Bailly. On the spectra of nozzle-exit velocity disturbances in initially nominally turbulent, transitional jets. Physics of Fluids, 2011, 23, pp.091702. 10.1063/1.3642642 . hal-00691034

\section{HAL Id: hal-00691034 https://hal.science/hal-00691034}

Submitted on 14 Jun 2012

HAL is a multi-disciplinary open access archive for the deposit and dissemination of scientific research documents, whether they are published or not. The documents may come from teaching and research institutions in France or abroad, or from public or private research centers.
L'archive ouverte pluridisciplinaire $\mathbf{H A L}$, est destinée au dépôt et à la diffusion de documents scientifiques de niveau recherche, publiés ou non, émanant des établissements d'enseignement et de recherche français ou étrangers, des laboratoires publics ou privés. 


\title{
On the spectra of nozzle-exit velocity disturbances in initially nominally turbulent, transitional jets
}

\author{
Christophe Bogey, ${ }^{\text {a) }}$ Olivier Marsden, ${ }^{\text {b) }}$ and Christophe Bailly ${ }^{\mathrm{c})}$ \\ Laboratoire de Mécanique des Fluides et d'Acoustique, UMR CNRS 5509, Ecole Centrale de Lyon, \\ Université de Lyon, 69134 Ecully Cedex, France
}

(Received 26 April 2011; accepted 15 August 2011; published online 26 September 2011)

\begin{abstract}
In a recent paper by C. Bogey, O. Marsden, and C. Bailly ["Large-eddy simulation of the flow and acoustic fields of a Reynolds number $10^{5}$ subsonic jet with tripped exit boundary layers," Phys. Fluids 23(3), 035104 (2011)], simulation results were presented for round jets with tripped boundary layers, displaying nozzle-exit conditions typical of initially nominally turbulent, transitional jets, namely laminar mean velocity profiles and high fluctuation intensities. The velocity spectra evaluated just downstream of the nozzle exit are re-examined here with respect to literature data. They agree qualitatively very well with spectra obtained in a fully turbulent pipe flow using direct numerical simulation. The wave numbers dominating in the azimuthal direction are also consistent with measurements of spanwise energy distribution in fully turbulent boundary layers. The initial turbulent structures in the jets, therefore, appear to be organized similarly to those in fully developed wall-bounded flows. C 2011 American Institute of Physics. [doi:10.1063/1.3642642]
\end{abstract}

The effects of nozzle-exit conditions on jet flows have been investigated by many researchers since the midseventies. They have been found to be especially strong for laboratory jets whose diameter-based Reynolds numbers are around $10^{5}$. In these jets at neither low nor high Reynolds numbers, a large variety of intermediate transitional initial states may indeed be encountered between the fully laminar state and the fully turbulent state, depending on the facility and on whether the jet boundary layers are tripped. ${ }^{1-8}$ The jets can in particular be initially nominally turbulent, in Zaman's own terms ${ }^{5,6}$ when they exhibit, at the nozzle exit, mean velocity profiles in agreement with the Blasius laminar profile together with peak fluctuation levels around $10 \%$ of the jet core velocity $u_{j}$. Such conditions have for instance been observed experimentally by Batt, ${ }^{1}$ Hussain and Zedan, ${ }^{3,4}$ and Zaman $^{5,6}$ in tripped jets characterized by initial momentumthickness Reynolds numbers $\operatorname{Re}_{\theta}=u_{j} \delta_{\theta} / \nu$ around 400, between 180 and 350, and between 900 and 2250, respectively, where $\delta_{\theta}$ is the nozzle-exit boundary-layer momentum thickness and $\nu$ is the kinematic molecular viscosity.

As it is now becoming possible to compute laboratoryscale jets thanks to the increase in computer power and to the implementation of highly accurate methods, it appears interesting, as a stepping stone between past simulations of initially laminar jets ${ }^{9,10}$ and future simulations of initially fully turbulent jets, ${ }^{11}$ to numerically study initially nominally turbulent jets. This was recently done by the authors ${ }^{12}$ using large-Eddy simulation (LES) for Mach number 0.9, round jets whose boundary layers are tripped inside a pipe nozzle in order to obtain, at the exit, laminar mean velocity profiles of Reynolds number $\operatorname{Re}_{\theta}=900$ and peak axial turbulent intensities $u_{e}^{\prime} \simeq 0.09 u_{j}$. Based on the use of different meshes and on analyses of the LES quality, the solutions determined

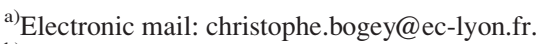

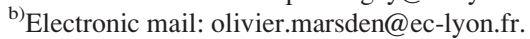

${ }^{c)}$ Electronic mail: christophe.bailly@ec-lyon.fr.
}

at higher resolutions were shown to be practically gridconverged, numerically accurate as well as physically relevant. Special attention was paid to the axial velocity spectra in the shear layers close to the nozzle exit. Broadband spectra as a function of both frequency and azimuthal wave number were found. Furthermore, dominant components centered around $k_{\theta} \delta_{\theta} / r_{0} \simeq 0.8$ were noticed in the azimuthal direction regardless of the boundary-layer thickness, where $k_{\theta}$ is the dimensionless azimuthal wave number $\left(k_{\theta}=0\right.$ for the axisymmetric mode, $k_{\theta}=1$ for mode 1 , etc.) and $r_{0}$ is the pipe radius. The origin of such features in transitional round jets was unfortunately not discussed.

In an attempt to clarify this point, the initial velocity spectra obtained in the above-mentioned LES study for two tripped jets with identical exit boundary-layer conditions are re-examined in the present letter. They are in particular compared to reference data available in the literature for fully turbulent boundary layers, ${ }^{13,14}$ channel, ${ }^{15}$ and pipe ${ }^{16}$ flows, which are known to exhibit similar velocity spectra. ${ }^{16-20}$ The two jets are those considered in the simulations referred to as Jetring $1024 \mathrm{drdz}$ and Jetring $1024 \mathrm{drdz} 2 \delta_{\theta}$ in the original paper, ${ }^{12}$ for which satisfactory grid-convergence is achieved. For both jets, the inflow parameters are chosen to specify, at $z=0$ at the exit of a pipe nozzle of length $2 r_{0}$, laminar mean velocity profiles of Reynolds number $\operatorname{Re}_{\theta}=900$, and peak turbulence levels $u_{e}^{\prime} \simeq 0.09 u_{j}$. This is performed, in practice, by imposing Blasius velocity profiles of thickness $\delta$ at the pipe inlet at $z=-2 r_{0}$ while adding low-amplitude random vortical fluctuations inside the pipe at $z \simeq-r_{0}$. The boundary-layer thickness is moreover equal to $\delta=0.15 r_{0}$ in Jetring $1024 \mathrm{drdz}$ but to $\delta=0.30 r_{0}$ in Jetring $1024 \operatorname{drdz} 2 \delta_{\theta}$, yielding $\delta_{\theta}=0.018 r_{0}$ and $\delta_{\theta}=0.036 r_{0}$, respectively.

As illustrations, the profiles of mean and rms axial velocities at the pipe exit are presented in Figure 1. The mean profiles correspond to the laminar profiles fixed at the pipe inlet, and the peak fluctuation levels are around $9 \%$ of the jet velocity as intended. The present jets are consequently 
(a)

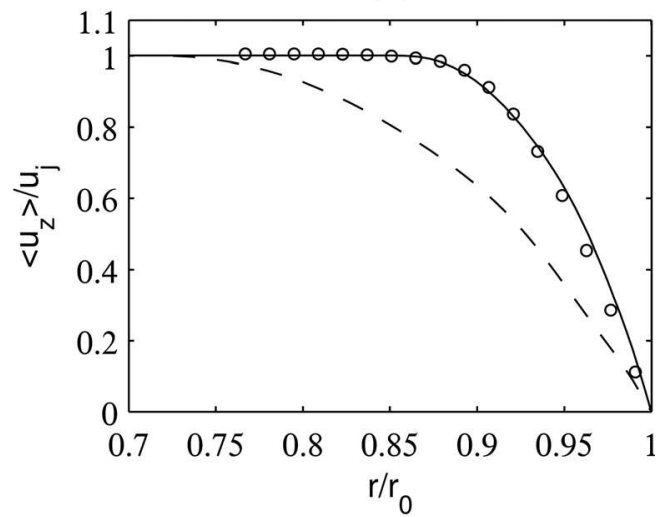

(b)

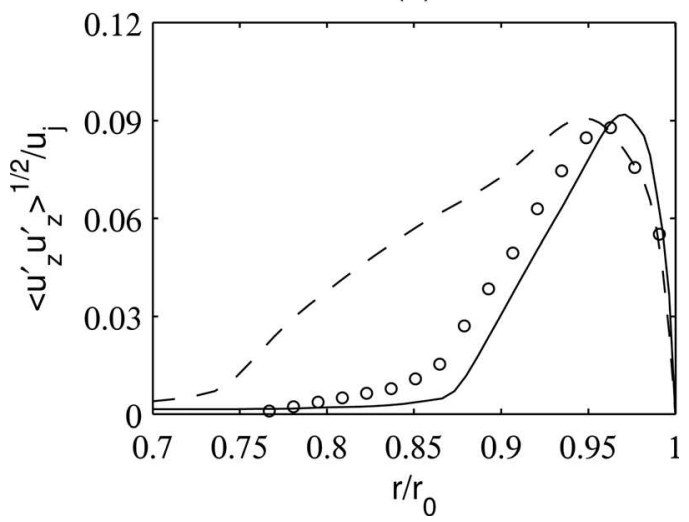

FIG. 1. Nozzle-exit profiles, at $z=0$, (a) of mean axial velocity $\left\langle u_{z}\right\rangle$ and (b) of the rms values of fluctuating axial velocity $u_{z}^{\prime}$, for (-) Jetring $1024 \mathrm{drdz}$ and (---) Jetring $1024 \mathrm{drdz} 2 \delta_{\theta}$; $(\bigcirc)$ measurements of $\operatorname{Zaman}^{5,6}$ for a tripped jet at $\operatorname{Re}_{D}=10^{5}$.

initially disturbed, but not fully turbulent. A relatively good agreement can also be noted between the exit velocity profiles in Jetring $1024 \mathrm{drdz}$ and measurements ${ }^{5,6}$ in a tripped jet at the same Reynolds number.

The jet simulations are detailed in the associated full paper. $^{12}$ Their main parameters are nevertheless given below. The LES were carried out using a solver of the 3-D filtered compressible Navier-Stokes equations in cylindrical coordinates $(r, \theta, z)$ using low-dissipation and low-dispersion finite differences and Runge-Kutta algorithm. ${ }^{21,22}$ The axis singularity is taken into account by the method of Mohseni and Colonius ${ }^{23}$ in combination with a specific treatment of azimuthal differentiation to alleviate the time-step limitation near the origin. ${ }^{24}$ Spectral-like filters ${ }^{25}$ are applied explicitly to the flow variables every time step in order to remove gridto-grid oscillations, as well as to relax subgrid-scale energy from scales at wave numbers close to the grid cut-off wave number while leaving larger scales mostly unaffected. ${ }^{12,26,27}$ The grid in Jetring $1024 \mathrm{drdz}$ contains $n_{r} \times n_{\theta} \times n_{z}=256$ $\times 1024 \times 962=252 \times 10^{6}$ points, and is characterized by radial, azimuthal, and axial mesh spacings $\Delta r=0.0036 r_{0}$ at $r=r_{0}, r_{0} \Delta \theta=0.0061 r_{0}$, and $\Delta z=0.0072 r_{0}$ between $z=-r_{0}$ and $z=0$. The grid in Jetring $1024 \operatorname{drdz} 2 \delta_{\theta}$ is that of Jetring $1024 \mathrm{drdz}$ limited axially to $z=8 r_{0}$. Because of the doubling of the boundary-layer thickness, the second simulation is thus performed at twice the effective resolution. (a)

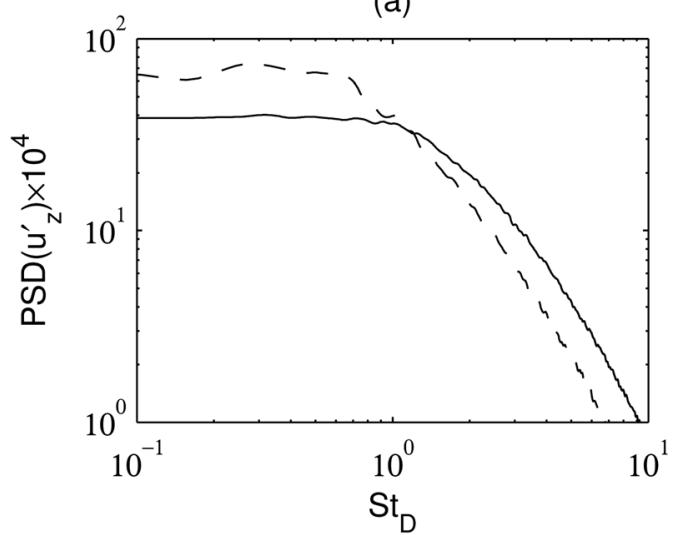

(b)

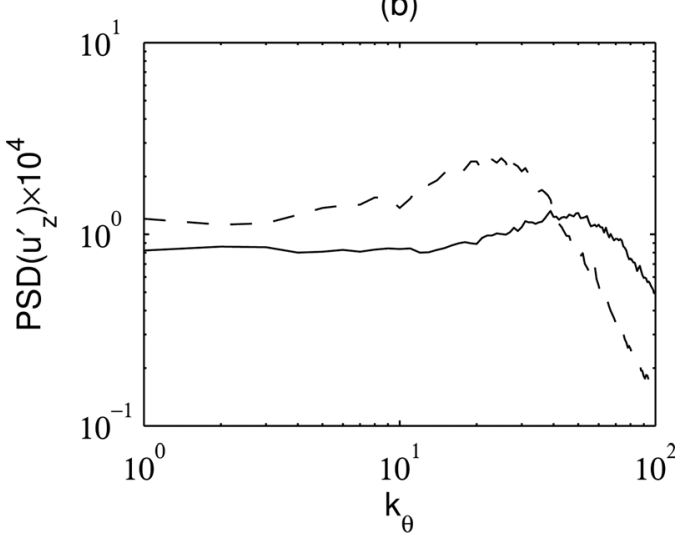

FIG. 2. Power spectral densities (PSD) normalized by $u_{j}$ of axial fluctuating velocity $u_{z}^{\prime}$, as functions (a) of Strouhal number $\mathrm{St}_{D}=f D / u_{j}$ and (b) of azimuthal wavenumber $k_{\theta}$, for (-) Jetring $1024 \mathrm{drdz}$ at $r=r_{0}$ and $z=0.4 r_{0}$ and (-- ) Jetring1024drdz $2 \delta_{\theta}$ at $r=r_{0}$ and $z=0.8 r_{0}$.

The properties of the jet initial disturbances are investigated by calculating spectra of the fluctuating axial velocity at $r=r_{0}$ near the nozzle lip, at $z=0.4 r_{0}$ in Jetring $1024 \mathrm{drdz}$ and $z=0.8 r_{0}$ in Jetring1024drdz $2 \delta_{\theta}$, corresponding to $z=22 \delta_{\theta}=2.7 \delta$ in both cases. This location is chosen very close to the nozzle exit in order to avoid the turbulence properties being appreciably affected by the mixing-layer development. The frequency spectra are represented versus the Strouhal number $\mathrm{St}_{D}=f D / u_{j}$ in Fig. 2(a), where $f$ is the frequency and $D=2 r_{0}$. They are rather flat up to $\mathrm{St}_{D} \simeq 1$ in Jetring $1024 \mathrm{drdz}$, and to $\mathrm{St}_{D} \simeq 0.5$ in Jetring $1024 \mathrm{drdz} 2 \delta_{\theta}$, and rapidly decrease for higher Strouhal numbers. The spectra as a function of the azimuthal wave number $k_{\theta}$ are shown in Fig. 2(b). For both jets, the energy of initial velocity fluctuations is distributed over a large range of azimuthal modes. Wave numbers centered around $k_{\theta} \simeq 46$ in Jetring $1024 \mathrm{drdz}$ and $k_{\theta} \simeq 24$ in Jetring1024drdz $2 \delta_{\theta}$ are, however, clearly dominating.

The spectra were previously ${ }^{12}$ represented versus $\mathrm{St}_{\theta}$ $=f \delta_{\theta} / u_{j}$ and $k_{\theta} \delta_{\theta} / r_{0}$ instead of $\mathrm{St}_{D}$ and $k_{\theta}$, respectively, to take the difference in boundary-layer thickness into account. The results for Jetring $1024 \mathrm{drdz}$ and Jetring $1024 \mathrm{drdz} 2 \delta_{\theta}$ appeared to collapse well, indicating that they are practically grid-independent. Peak components in the azimuthal spectra were also located around normalized wave numbers $k_{\theta} \delta_{\theta} / r_{0}$ $\simeq 0.8$. 
(a)

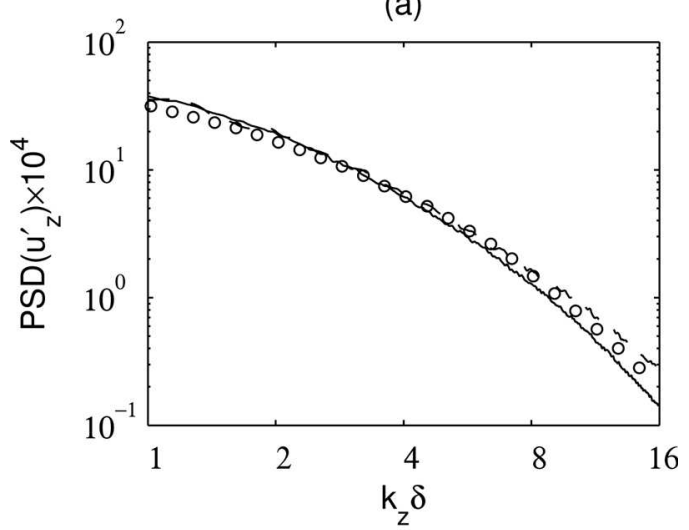

(b)

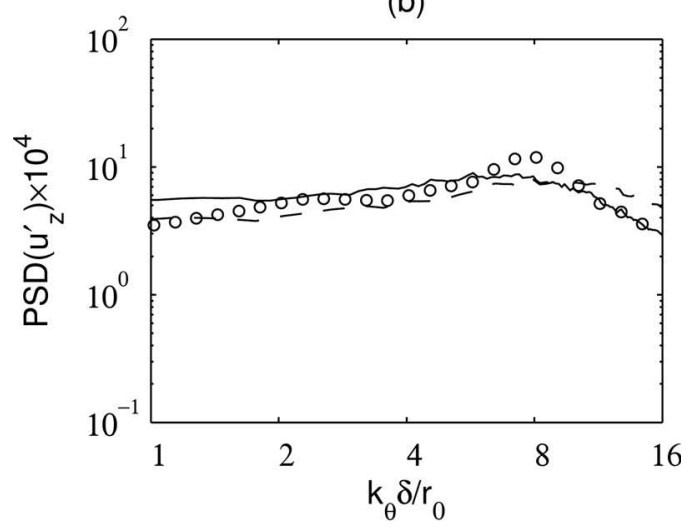

FIG. 3. PSD normalized by $u_{j}$ of axial fluctuating velocity $u_{z}^{\prime}$, as functions of non-dimensional axial and azimuthal wavenumbers (a) $k_{z} \delta$ and (b) $k_{\theta} \delta / r_{0}$, for (-) Jetring1024drdz at $r=r_{0}$ and $z=0.4 r_{0}$, and $\left(-{ }_{-}\right.$) Jetring1024drdz2 $\delta_{\theta}$ at $r=r_{0}$ and $z=0.8 r_{0} ;(\bigcirc)$ DNS data of Eggels et al. ${ }^{16}$ for a fully developed turbulent pipe flow, shifted arbitrarily in magnitude for the comparison.

In order to shed light on the physics of initial turbulence in the present transitional jets, the spectra are now plotted versus axial and azimuthal wave numbers $k_{z} \delta$ and $k_{\theta} \delta / r_{0}$ in Figs. 3(a) and 3(b), using a scaling with the boundary-layer thickness $\delta$ frequently encountered in the literature for wallbounded flows. The axial wave number $k_{z}$ is here estimated from the Strouhal number $\mathrm{St}_{D}$ using Taylor's hypothesis of a frozen turbulence being convected at the velocity $u_{j} / 2$. As expected, the spectra from Jetring $1024 \mathrm{drdz}$ and Jetring $1024 \mathrm{drdz} 2 \delta_{\theta}$ do not differ significantly. More interestingly, their shapes are consistent with direct numerical simulation (DNS) data obtained in fully turbulent flat-plate boundary layers, channel, and pipe flows, respectively, by Spalart ${ }^{13}$ at $\operatorname{Re}_{\theta}=1410$, Kim et al. ${ }^{15}$ at $\operatorname{Re}_{\theta}=287$, and Eggels et al. ${ }^{16}$ at $\operatorname{Re}_{\theta}=236$. To support this assertion, the spectra of fluctuating axial velocity provided by the latter authors in a fully turbulent pipe flow at a distance from the wall of $y^{+} \simeq 30$, or equivalently of $y / \delta \simeq 0.17$, are shown in Figs. 3(a) and 3(b), shifted arbitrarily in magnitude for the comparison. A very good qualitative agreement is noticed between the jet LES and pipe-flow DNS results, for both axial and azimuthal spectra, over the whole range of wave numbers $1 \leq k_{z} \delta, k_{\theta} \delta / r_{0} \leq 16$. The wave numbers dominating in the azimuthal direction are found for $k_{\theta} \delta / r_{0} \simeq 7-8$ in all cases. The turbulent structures near the nozzle exit of the present circular jets therefore appear to be organized in a similar fashion to those in a fully turbulent pipe flow.

Regarding the strongest contributions to the azimuthal spectra, it can be worth mentioning the experimental work carried out by Tomkins and Adrian. ${ }^{14}$ These authors succeeded in identifying the most energetic modes in turbulent boundary layers at $\operatorname{Re}_{\theta}=1015$ and 7705 using particle-imagevelocimetry (PIV) measurements. They observed at both Reynolds numbers that the spanwise distribution of streamwise energy throughout the logarithmic region up to $y / \delta=0.2$ is dominated by large-scale elongated ${ }^{28}$ structures with spacing $\lambda / \delta=0.75-0.9$, yielding $k \delta=7-8.4$ in terms of dimensionless spanwise wavenumber. Even if structural differences exist between velocity spectra for pipes/channels and boundary layers, ${ }^{17}$ the peak wave numbers $k_{\theta} \delta / r_{0} \simeq 7$ emerging in the azimuthal spectra of the axial fluctuating velocity for Jetring $1024 \mathrm{drdz}$ and Jetring $1024 \mathrm{drdz} 2 \delta_{\theta}$ in Fig. 3(b) fall within that range. This suggests close similarities in the spatial arrangements of large turbulent scales at the nozzle exit of the present transitional jets and in fully turbulent boundary layers.

As a concluding remark, the nature of nozzle-exit conditions in transitional round jets, and their effects on the jet flow and sound field, continue to be the subject of much debate. $^{1-8,10}$ The resemblances reported here between the velocity spectra close to the jet exit and those in fully developed wall-bounded flows provide some new results in this field, and support that initially nominally turbulent jets can be considered as a physically justified model of initially fully turbulent jets.

This work was granted access to the HPC resources of the Institut du Développement et des Ressources en Informatique Scientifique (IDRIS) under the allocation 2011-020204 made by GENCI (Grand Equipement National de Calcul Intensif).

${ }^{1}$ R. G. Batt, "Some measurements on the effect of tripping the twodimensional shear layer," AIAA J. 13(2), 245 (1975).

${ }^{2}$ W. G. Hill, R. C. Jenkins, and B. L. Gilbert, "Effects of the initial boundarylayer state on turbulent jet mixing," AIAA J. 14(11), 1513 (1976).

${ }^{3}$ A. K. M. F. Hussain and M. F. Zedan, "Effects of the initial condition on the axisymmetric free shear layer: Effects of the initial momentum thickness," Phys. Fluids 21(7), 1100 (1978).

${ }^{4}$ A. K. M. F. Hussain and M. F. Zedan, "Effects of the initial condition on the axisymmetric free shear layer: Effects of the initial fluctuation level," Phys. Fluids 21(9), 1475 (1978).

${ }^{5}$ K. B. M. Q. Zaman, "Far-field noise of a subsonic jet under controlled excitation,” J. Fluid Mech. 152, 83 (1985).

${ }^{6}$ K. B. M. Q. Zaman, "Effect of the initial condition on subsonic jet noise," AIAA J. 23(9), 1370 (1985).

${ }^{7}$ J. E. Bridges and A. K. M. F. Hussain, "Roles of initial conditions and vortex pairing in jet noise," J. Sound Vib. 117(2), 289 (1987).

${ }^{8}$ P. J. Morris and K. B. M. Q. Zaman, "Velocity measurements in jets with application to noise source modelling," J. Sound Vib. 329(4), 394 (2009).

${ }^{9}$ J. B. Freund, "Noise sources in a low-Reynolds-number turbulent jet at Mach 0.9," J. Fluid Mech. 438, 277 (2001).

${ }^{10} \mathrm{C}$. Bogey and C. Bailly, "Influence of nozzle-exit boundary-layer conditions on the flow and acoustic fields of initially laminar jets," J. Fluid Mech. 663, 507 (2010).

${ }^{11}$ A. Uzun and M. Hussaini, "Investigation of high frequency noise generation in the near-nozzle region of a jet using large eddy simulation," Theor. Comput. Fluid Dyn. 21(4), 291 (2007).

${ }^{12}$ C. Bogey, O. Marsden, and C. Bailly, "Large-eddy simulation of the flow and acoustic fields of a Reynolds number $10^{5}$ subsonic jet with tripped exit boundary layers," Phys. Fluids 23(3), 035104 (2011). 
${ }^{13}$ P. R. Spalart, "Direct simulation of a turbulent boundary layer up to $R_{\theta}=1410$, , J. Fluid Mech. 187, 61 (1988).

${ }^{14}$ C. D. Tomkins and R. J. Adrian, "Energetic spanwise modes in the logarithmic layer of a turbulent boundary layer," J. Fluid Mech. 545, 141 (2005).

${ }^{15}$ J. Kim, P. Moin, and R. Moser, "Turbulence statistics in fully developed channel flow at low Reynolds number," J. Fluid Mech. 177, 133 (1987).

${ }^{16}$ J. G. M. Eggels, F. Unger, M. H. Weiss, J. Westerweel, R. J. Adrian, R. Friedrich, and F. T. M. Nieuwstadt, "Fully developed turbulent pipe flow: a comparison between direct numerical simulation and experiment," J. Fluid Mech. 268, 175 (1994).

${ }^{17}$ J. P. Monty, N. Hutchins, H. C. H. Ng, I. Marusic, and M. S. Chong, "A comparison of turbulent pipe, channel and boundary layer flows," J. Fluid Mech. 632, 431 (2009).

${ }^{18} \mathrm{~S}$. Ghosh, H. Foysi, and R. Friedrich, "Compressible turbulent channel and pipe flow: similarities and differences," J. Fluid Mech. 648, 155 (2010).

${ }^{19}$ J. Jiménez, S. Hoyas, M. P. Simens, and Y. Mizuno, "Turbulent boundary layers and channels at moderate Reynolds numbers," J. Fluid Mech. 657, 335 (2010).

${ }^{20}$ H. C. H. Ng, J. P. Monty, N. Hutchins, M. S. Chong, and I. Marusic, "Comparison of turbulent channel and pipe flows with varying Reynolds number," Exp. Fluids (to be published).
${ }^{21}$ C. Bogey and C. Bailly, "A family of low dispersive and low dissipative explicit schemes for flow and noise computations," J. Comput. Phys. 194(1), 194 (2004).

${ }^{22}$ J. Berland, C. Bogey, O. Marsden, and C. Bailly, "High-order, low dispersive and low dissipative explicit schemes for multiple-scale and boundary problems," J. Comput. Phys. 224(2), 637 (2007).

${ }^{23} \mathrm{~K}$. Mohseni and T. Colonius, "Numerical treatment of polar coordinate singularities," J. Comput. Phys. 157(2), 787 (2000).

${ }^{24}$ C. Bogey, N. de Cacqueray, and C. Bailly, "Finite differences for coarse azimuthal discretization and for reduction of effective resolution near origin of cylindrical flow equations," J. Comput. Phys. 230(4), 1134 (2011).

${ }^{25} \mathrm{C}$. Bogey, N. de Cacqueray, and C. Bailly, "A shock-capturing methodology based on adaptative spatial filtering for high-order non-linear computations," J. Comput. Phys. 228(5), 1447 (2009).

${ }^{26} \mathrm{C}$. Bogey and C. Bailly, "Large Eddy simulations of transitional round jets: influence of the Reynolds number on flow development and energy dissipation," Phys. Fluids 18(6), 065101 (2006).

${ }^{27} \mathrm{C}$. Bogey and C. Bailly, "Turbulence and energy budget in a selfpreserving round jet: Direct evaluation using large-eddy simulation," J. Fluid Mech. 627, 129 (2009).

${ }^{28}$ C. D. Tomkins and R. J. Adrian, "Spanwise structure and scale growth in turbulent boundary layers," J. Fluid Mech. 490, 37 (2003). 